\title{
Les protéines antisens des virus HTLV
}

\author{
Clément Caté ${ }^{1}$ \\ Émilie Larocque ${ }^{1}$ \\ Jean-Marie Peloponese ${ }^{2}$ \\ Jean-Michel Mesnard² \\ Éric Rassart ${ }^{1}$ \\ Benoît Barbeau ${ }^{1}$ \\ ${ }^{1}$ Département des sciences \\ biologiques, Centre de recherche \\ BioMed, université du Québec \\ à Montréal, \\ 141, avenue du Président-Kennedy, \\ H2X 1Y4, Montréal, Québec, Canada \\ $<$ barbeau.benoit@uqam.ca> \\ ${ }^{2}$ Institut de recherche en infectiologie \\ de Montpellier (IRIM), université de \\ Montpellier, CNRS, Montpellier, France
}

\begin{abstract}
Résumé. Les virus T-lymphotropiques humains (HTLV) sont composés de quatre membres : HTLV-1, 2, 3 et 4. Issus d'une transmission de virus simiens, les virus HTLV sont capables d'infecter plusieurs types de cellules du système immunitaire. HTLV-1 est le premier rétrovirus humain isolé responsable de pathologies chez l'individu infecté. Bien que l'expression des gènes des rétrovirus dépende généralement du promoteur situé dans leur LTR $5^{\prime}$, il a été démontré que le LTR 3 'des HTLV possédait aussi une activité promotrice responsable de la production d'un transcrit antisens in vivo. Ces transcrits sont capables de produire des protéines dites antisens, nommées HBZ, APH-2, APH-3 et APH-4, respectivement pour HTLV-1, 2, 3 et 4. La transcription antisens chez HTLV-1 a été analysée en détail et la protéine HBZ est la plus étudiée des quatre protéines antisens. Il est aujourd'hui avéré qu'elle possède des rôles importants pour la réplication virale et le développement de la leucémie. Peu d'études ont cependant été réalisées sur la transcription antisens chez HTLV-2 et encore moins chez HTLV-3/4, bien qu'il semble très probable que la transcription antisens joue également un rôle crucial dans leur processus infectieux.
\end{abstract}

Mots clés : virus T-lymphotropiques humains, protéines antisens, HBZ, APH, ATL

\begin{abstract}
There are four human T-lymphotropic viruses (HTLV-1, 2, 3, 4) that have emerged from the transmission of simian viruses. HTLV-1 was the first retrovirus to be shown to be responsible for a human pathology. The expression of retroviral genes depends mostly on their $5^{\prime}$ LTR, but it was revealed that HTLV have a promoter in their $3^{\prime} \mathrm{LTR}$, capable of transcription from the antisense strand of their genome. These transcripts can be translated into proteins named HBZ, APH-2, APH-3 and APH-4. Antisense transcription in HTLV-1 and its encoded protein HBZ have been thoroughly studied and it has been suggested that HBZ plays an important role in viral replication and the development of ATL. Very few studies have been conducted on antisense transcription from the three other viruses, although it is likely that these genes are also implicated in viral replication.
\end{abstract}

Key words: human T-lymphotropic virus, antisense protein, HBZ, APH, ATL

\section{Les HTLV}

HTLV-1 est historiquement le premier rétrovirus humain pathogène à avoir été identifié. Des études menées chez des patients atteints de lymphome [1] et de leucémie [2] sont parvenues à démontrer que HTLV-1 est l'agent causal de ces cancers. Des études ultérieures ont démontré l'existence d'un deuxième virus apparenté nommé

Tirés à part : B. Barbeau
HTLV-2, puis, au début des années 2000, deux autres virus de la famille HTLV, les types 3 et 4 , furent découverts chez des chasseurs camerounais [3, 4].

De nombreuses études phylogéniques ont clairement démontré que les HTLV sont apparus chez l'être humain suite à de multiples transmissions de virus simiens nommés STLV (Simian T-lymphotropic virus) vers l'homme [5-7]. Le virus est transmis principalement par morsure [8], ainsi que par la consommation de viande de singes et par contact avec des liquides biologiques de singes vivants [9]. La répartition des HTLV en Afrique est d'ailleurs très 
similaire à celle du VIH-1 (virus de l'immunodéficience humaine de type 1), qui est également issu d'une zoonose simienne [10].

HTLV-1 est le virus le plus prévalent de cette famille et il est estimé qu'au moins 5 à 10 millions de personnes sont actuellement infectées [11]. La majorité des porteurs du virus habitent l'Afrique centrale et équatoriale, mais le virus est aussi très prévalent au Japon et en Amérique du Sud, en plus d'être présent sur les autres continents. HTLV-2 semble aussi s'être répandu sur tous les continents, étant particulièrement endémique chez certains groupes ethniques de l'Afrique centrale et de différentes régions de l'Amérique [12-14]. Le nombre d'individus infectés a été estimé à plusieurs millions, principalement chez les consommateurs de drogues intraveineuses, bien qu' aucun recensement majeur n'ait encore été effectué [15]. Très peu de cas d'infection par HTLV-3 ont été répertoriés et ces derniers semblent limités au Cameroun [3, 4, 9]. Quant au HTLV-4, il n'existe que trois cas identifiés, un au Cameroun et deux au Gabon, et ce virus semble être le plus ancien représentant des HTLV $[16,17]$. Des études ont rapidement démontré l'existence d'un équivalent simien du HTLV-3, nommé STLV-3 [18] et très récemment un homologue simien du HTLV-4 a pu être identifié chez une population de gorilles camerounais [19], confirmant que HTLV-4, tout comme les autres virus HTLV, aurait été transmis à l'homme par infection zoonotique.

Bien que les HTLV démontrent généralement un large tropisme in vitro, les lymphocytes $\mathrm{T}$ sont les cellules les plus abondamment infectées chez les individus séropositifs. Leur infection serait dépendante de contacts cellule-cellule, mécanisme largement plus efficace qu'une infection par des particules virales libres [20]. La glycoprotéine de surface de HTLV-1 reconnaît spécifiquement un complexe composé du sulfate d'héparane de protéoglycans, la neuropiline-1 et le récepteur au glucose GLUT-1, qui semblent impliqués de façon séquentielle pour promouvoir l'entrée virale [21-24]. Des différences au niveau de l'entrée et l'utilisation de ces récepteurs ont été notées pour HTLV-2 et HTLV-3 [25].

HTLV- 1 et 2 sont capables de provoquer plusieurs maladies distinctes chez l'homme. La période de latence clinique des patients infectés par HTLV-1 peut être de plusieurs décennies, et, dans un faible pourcentage, mène à l'apparition d'une leucémie à cellules $\mathrm{T}$ (adult T cell leukemia/lymphoma : ATL) (approximativement $5 \%$ des cas d'infection) ainsi que d'une maladie neurodégénérative appelée HAM/TSP (HTLV-1-associated myelopathy/tropical spastic paraparesis) (moins de $4 \%$ des cas d'infection), qui cause une perte de sensibilité des extrémités et un mauvais fonctionnement des sphincters [26,27]. Des symptômes semblables à la myélopathie associée au virus HTLV-1 ont pu être observés chez des patients infectés par HTLV-2 [28]. Il n'existe que très peu de données sur les pathologies que pourraient entraîner HTLV-3 et 4 [29]. Cer- taines similarités existantes entre HTLV-3 et HTLV-1, qui seront discutées plus loin, suggèrent que HTLV-3 pourrait néanmoins avoir un pouvoir transformant sur les lymphocytes $\mathrm{T}[30]$.

\section{L'organisation génomique des HTLV}

Comme tous les rétrovirus, le génome des HTLV est bordé de séquences LTR (long terminal repeat) (figure 1) dont les rôles sont multiples [31]. Les LTR contiennent les promoteurs de transcription des gènes viraux, possèdent les sites d'amorçage de la transcription inverse de l'ARN viral et servent à l'étape d'intégration du provirus dans l'ADN génomique des cellules infectées [32,33]. Dans sa région $3^{\prime}$, le LTR agit comme signal de terminaison de la transcription par l'intermédiaire d'un signal de polyadénylation et forme une structure ARN nommée RexRE (Rex-responsive element) responsable de la régulation du transport nucléocytoplasmique des ARN non-épissés ou mono-épissés. Les LTR sont séparés en trois régions distinctes (U3, R, U5) qui assurent ces différents rôles. La région U3 contient le promoteur viral, constitué d'une boîte TATA ainsi que les éléments appelés TRE (Tax-responsive element). Ces derniers stimulent la transcription via un complexe composé de la protéine virale Tax et de certains facteurs de transcription, tels que $\mathrm{CREB}$, qui permettent la liaison à des séquences nommées vCRE (viral CRE) [32,34]. D'autres sites de liaison à différents facteurs de transcription ont été décrits, tels que $\mathrm{Sp} 1$ et NF-кB, et semblent contribuer à la transcription des gènes viraux dépendante du LTR $5^{\prime}$ [32, 35-37]. Possédant un génome de seulement $9 \mathrm{~kb}$, les HTLV ont recours à plusieurs épissages et sauts ribosomiques afin d'exprimer tous leurs gènes. Les protéines issues de la transcription «sens » sont :

- la polyprotéine Gag qui forme la particule virale ;

- les enzymes virales comprenant la protéase, la transcriptase inverse et l'intégrase ;

- les glycoprotéines de l'enveloppe (sous-unités TM et $\mathrm{SU})$;

- deux protéines régulatrices impliquées dans l'expression du génome viral (Tax et Rex) ;

- et enfin, les protéines dites auxiliaires qui sont différentes entre les HTLV et qui généralement interagissent avec les protéines cellulaires sans pour autant être essentielles à la réplication virale (figure 1 ).

\section{La transcription dite antisens}

La transcription antisens est, par définition, basée sur le brin complémentaire du brin codant d'un gène préalablement identifié. Elle repose fréquemment sur l'existence de promoteurs bidirectionnels, parfois dépendants de 


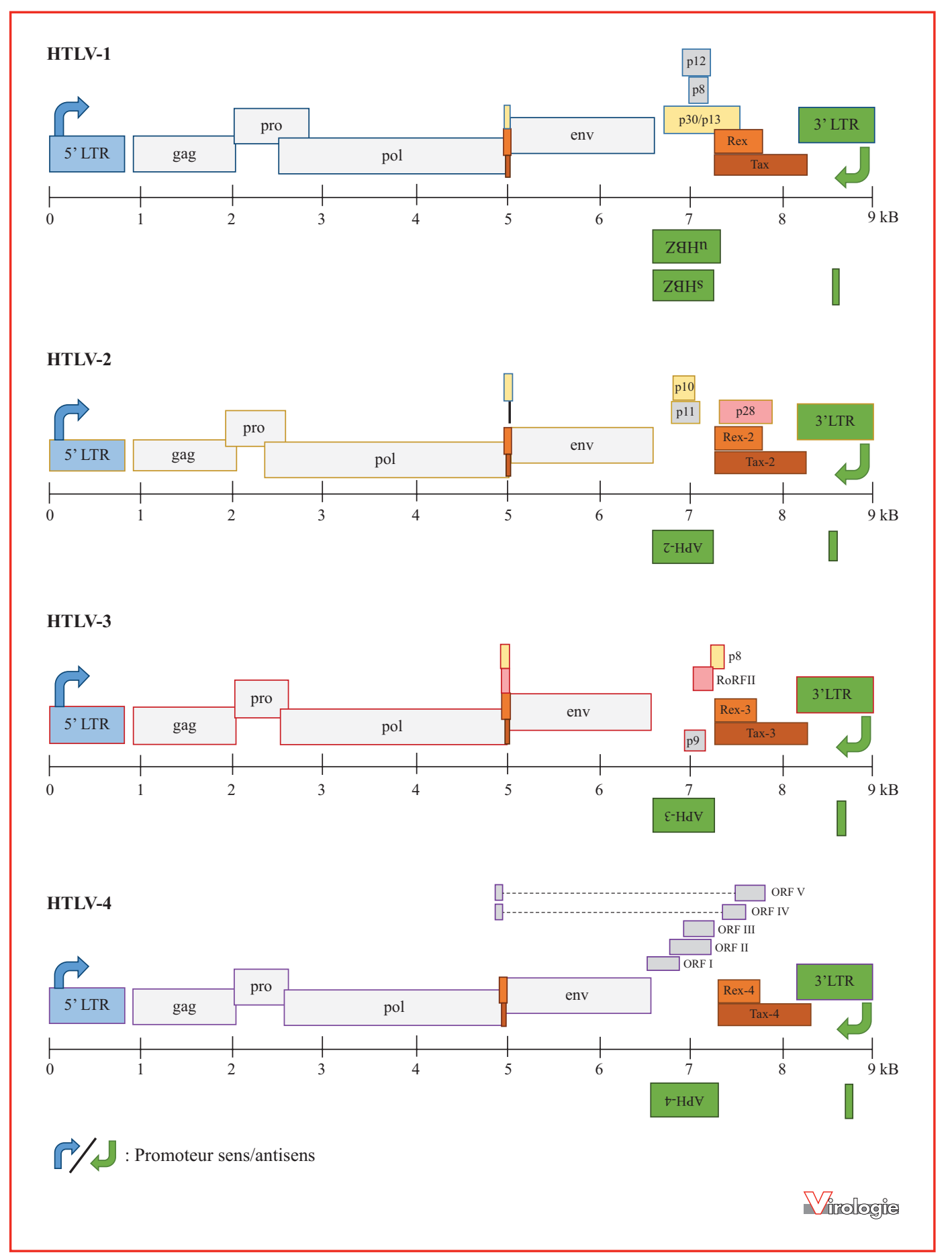

Figure 1. Représentation schématique des génomes des virus HTLV-1,2,3 et 4, avec leurs principaux épissages, leurs ORFs sens et antisens, et l'emplacement de leurs promoteurs. Seul HTLV-1 produit une forme épissée (shbz) et non-épissée (uhbz) de son transcrit antisens. L'expression des transcrits antisens est généralement dépendante d'un promoteur situé dans le LTR $3^{\prime}$. HTLV-4 possède cinq ORFs sens qui ont été identifiés uniquement in silico, et qui pourraient coder des protéines accessoires. 
facteurs transcriptionnels similaires (bien qu'ils puissent aussi être indépendants) [38]. L'orientation de ces gènes peut être opposée (tête-à-tête avec un gène sens), convergente (queue-à-queue) et/ou même entièrement chevauchante. Les transcrits antisens peuvent posséder un cadre de lecture ouvert codant une protéine ou être noncodants. Il est probable que la transcription antisens représente une importante proportion de la totalité des transcrits chez les mammifères. Il a, par exemple, été estimé que la proportion des transcrits antisens chez la souris est de $20 \%$ des transcrits totaux [39]. La grande majorité des transcrits antisens est malgré tout non-codante, suggérant que leur rôle est essentiellement régulateur [40].

Les virus sont aussi connus pour faire usage de la transcription antisens et cela n'est guère étonnant que cette stratégie de transcription soit employée par les rétrovirus pour augmenter leur capacité codante, considérant l'importante compacité de leur génome [41]. Pour la première fois en 1988, la production d'une protéine virale à partir de transcrits antisens fut suggérée dans le cas du VIH-1 [42]. L'hypothèse que les rétrovirus ont recours à la transcription antisens a été ensuite confirmée par une étude démontrant l'expression de transcrits antisens dans des cellules infectées par HTLV-1 [43].

Les LTR des rétrovirus humains possèdent un promoteur bidirectionnel capable d'initier une transcription sens ou antisens et dont l'activité varie dans un sens ou un autre en fonction du type cellulaire, du rétrovirus et surtout de la présence ou non des transactivateurs viraux (Tax pour HTLV-1 ou Tat pour le VIH-1) [44]. En effet, en absence d'activateurs viraux, la production de transcrits antisens est plus efficace que celle de transcrits sens. Les rétrovirus complexes sembleraient ainsi coder des trans-activateurs viraux afin de favoriser la production de transcrits sens et en leur absence, leurs LTR seraient plutôt impliqués dans la production de transcrits antisens. D'ailleurs, il est intéressant de noter que, dans le cas du MLV (murine leukemia virus), qui est un rétrovirus simple (ne possédant que les gènes gag, pol, pro et env, l'activité basale du LTR est plus forte en sens qu'en antisens [44]. Dans le cas des HTLV, la transcription antisens produit des transcrits possédant un cadre de lecture ouvert, de multiples sites d'initiation et une queue poly(A), à partir desquels des protéines virales dites antisens sont produites. L'existence de différents sites d'initiation s'explique par l'absence de boîte TATA et la présence de sites de liaisons au facteur de transcription Sp1 [44, 45], connu pour être capable d'initier la transcription en absence de boîte TATA.

La transcription antisens de HTLV-1 a été de loin la plus étudiée et les protéines issues de ces transcrits antisens, nommées HBZ (HTLV-1 bZIP factor) ont un rôle crucial dans la réplication du virus et des pathologies associées [4648]. Les autres protéines antisens connues sont nommées respectivement APH-2, APH-3 et APH-4 (antisense protein of $H T L V-2 / 3 / 4$ ) et bien qu'elles aient été décrites et leurs transcrits analysés, leur rôle précis dans le cycle viral des virus n'a fait l'objet que de peu d'études [47].

\section{HTLV-1 et HBZ}

Le gène $h b z$ est transcrit sous deux formes différentes : une épissée et une non-épissée [45, 49-51]. La forme épissée possède des sites d'initiation dans les régions $\mathrm{U} 5$ et $\mathrm{R}$ du LTR 3', et la non-épissée dans les régions en aval du LTR $3^{\prime}[45,50,51]$. Chacune ainsi traduite donne des isoformes différentes de la protéine : uHBZ et sHBZ (pour unspliced et spliced $h b z$ ). La différence de séquence entre les deux isoformes est minime et correspond à seulement quelques acides aminés dans la partie $\mathrm{N}$-terminale ( 7 acides aminés chez uHBZ sont remplacés par 4 acides aminés différents chez sHBZ) [50]. Néanmoins, l'isoforme sHBZ est majoritaire dans les cellules infectées, ce qui semble être dû en partie à un plus haut taux d'ARNm et à une demi-vie plus longue de la protéine [45, 52]. sHBZ possède, dans sa partie C-terminale, un domaine bZIP riche en leucines, que l'on retrouve chez plusieurs facteurs de transcription eucaryotes de la même famille. Les motifs bZIP ont la capacité de se lier à l'ADN sur des séquences particulières, ainsi que de former des liaisons avec des domaines bZIP d'autres protéines. Les études principalement menées sur l'isoforme sHBZ ont ainsi pu démontrer que ce motif bZIP était nécessaire aux principales fonctions de la protéine. Grâce à ce domaine, sHBZ est capable d'interagir avec plusieurs facteurs de transcription cellulaires, soit entre autres CREB, CREB2, JunD, c-Jun, JunB et la sous-unité p65 du complexe NF-кB $[48,53]$. Suivant ces interactions, sHBZ module leur activation (souvent en agissant en tant que répresseur) et ainsi, l'expression d'un nombre important de gènes dont les gènes viraux.

Les membres de la famille ATF/CREB sont impliqués dans la régulation de la transcription sens par l'entremise de leur liaison aux régions CRE contenues dans le LTR 5' (figure 2). Alors que l'activation des facteurs CREB induite par Tax favorise la transcription sens, cette induction est contrebalancée par sHBZ qui lie ces facteurs, antagonisant ainsi l'action de Tax. Des études récentes ont permis d'établir que sHBZ pouvait également avoir un impact positif sur sa propre expression par l'intermédiaire d'un complexe incluant JunD et $\mathrm{Sp} 1$ formé à la région U5 du LTR 3' sur des sites de liaison Sp1 [45, 54]. La protéine sHBZ joue donc un rôle essentiel dans la régulation de l'expression virale en agissant comme régulateur négatif de la transcription sens, inhibant ainsi l'expression de Tax et la production de particules virales, tout en modulant positivement la transcription antisens et donc sa propre expression. Cette régulation de 


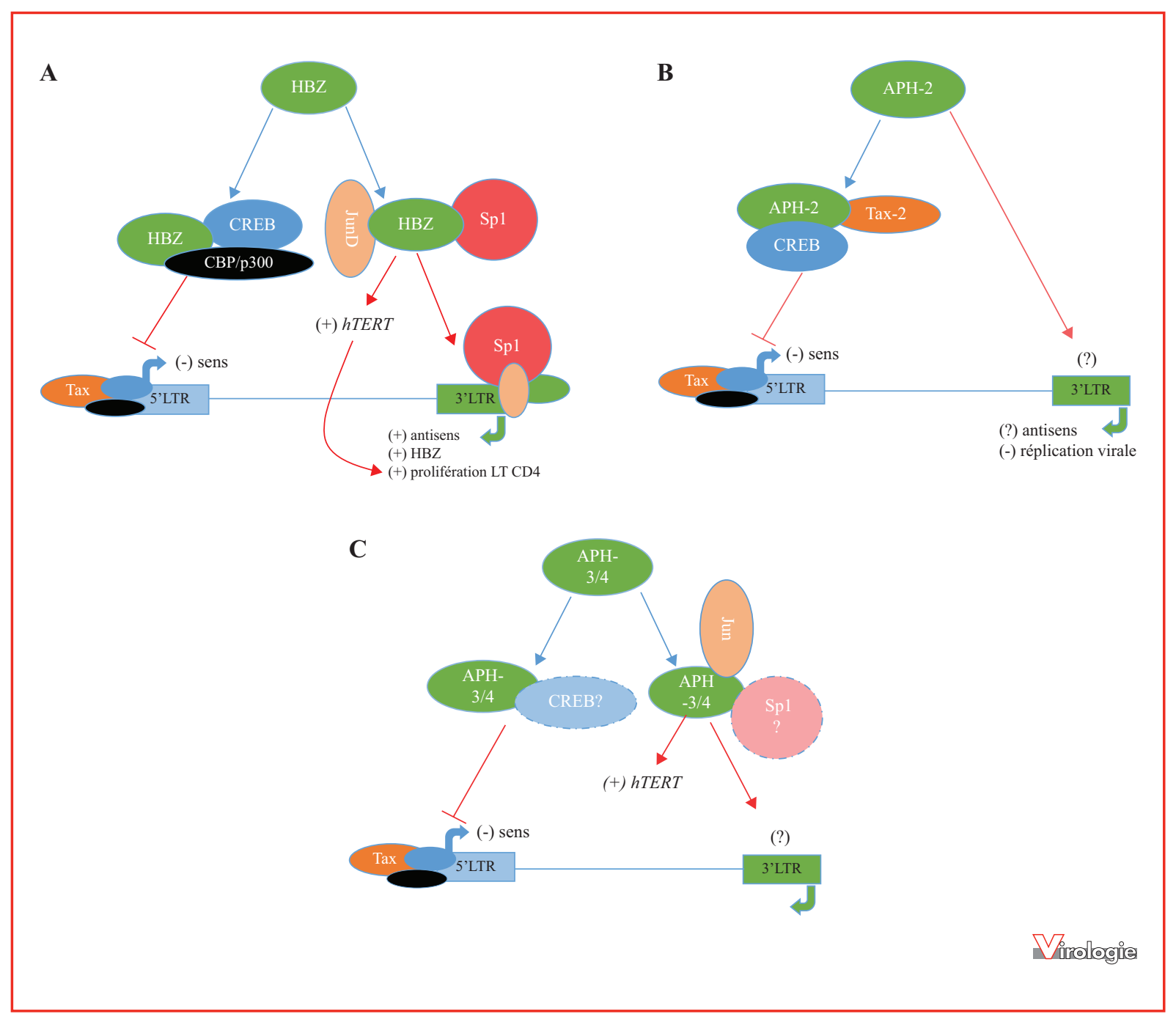

Figure 2. Différences d'action des protéines antisens des HTLVs sur l'expression des gènes viraux. HBZ peut interagir avec $C R E B$ et CBP/p300 afin d'empêcher leur recrutement par la protéine virale Tax et inhiber la transcription au LTR $5^{\prime}$. II recrute également JunD et Sp1 afin de favoriser la transcription antisens et l'expression du gène $h T E R T$ (hautement exprimé dans les cellules ATL). APH-2 est capable d'interagir directement avec Tax-2 et CREB et interfère avec leur action transactivatrice du 5'LTR. APH-3 et APH-4 inhibent l'activation Tax-dépendante, bien que le mécanisme d'action n'ait pas été éclairci. Ces deux protéines interagissent également avec les membres de la famille Jun, et, tout comme APH-2, mènent à l'activation de ces facteurs et l'expression de hTERT. L'activation de l'expression antisens par APH-3 et 4 n'a pas encore fait l'objet d'étude.

l'expression virale par HBZ pourrait expliquer les résultats obtenus par Arnold et al. dans un modèle in vivo de lapin démontrant que cette protéine contribuerait à la persistance virale [55].

L'impact positif de sHBZ sur la transcription JunDdépendante a été décrit dans d'autres études et a fortement été suggéré comme étant responsable de la haute expression du gène de la télomérase humaine (hTERT) dans les cellules ATL, impliquant ainsi sHBZ dans la transformation des lymphocytes T CD4+ en cellules leucémiques [56, 57]. L'implication de HBZ dans le développement de l'ATL a été un point central des recherches menées ces dernières années, qui ont proposé différents modes d'action de HBZ au niveau de la régulation de cascades signalétiques et de l'expression de gènes impliqués dans le contrôle du cycle cellulaire [53]. Bien que certaines études ont montré que HBZ ne soit pas essentielle à l'immortalisation induite par HTLV-1, il a néanmoins été démontré que HBZ agit positivement sur la prolifération des lymphocytes $\mathrm{T}$ [58] et que des souris transgéniques exprimant HBZ étaient sujettes à développer des lymphomes T [59]. Plusieurs mécanismes ont été proposés sur le pouvoir transformant de protéine 


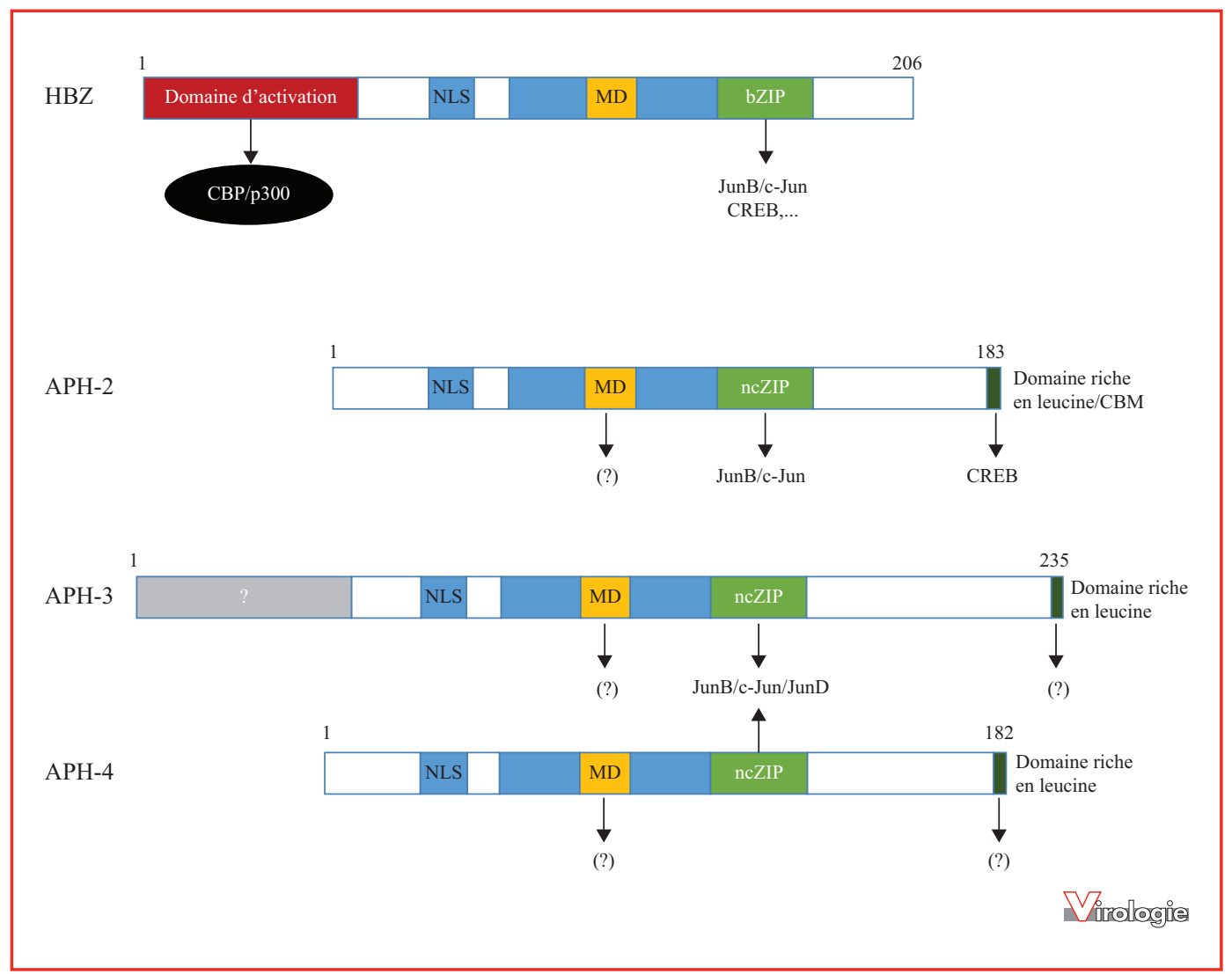

Figure 3. Comparaison entre les domaines fonctionnels des séquences en acides aminés d'HBZ, APH-2, 3 et 4 . HBZ possède un domaine d'activation $\mathrm{N}$-terminal fonctionnel qu'on ne retrouve pas chez APH-2, 3 et 4, mais une séquence ressemblante apparaît chez $\mathrm{APH}-3$. En bleu sont représentés les trois domaines de localisation nucléaire (NLS : Nuclear localisation signal) qui sont très conservés chez chacune des protéines antisens. Les bZIP et ncZIP ont pu être identifiés comme ayant un rôle important dans l'interaction avec les protéines cellulaires. Enfin, les courts domaines C-terminaux d'APH-2, 3 et 4 possèdent un motif riche en leucine capable également d'interagir avec des protéines. Pour APH-2, il permet d'interagir avec CREB (CBM : CREB-binding motif) mais son rôle n'a pas été élucidé chez APH-3 et 4. Les quatre protéines possèdent également un domaine riche en acide glutamique, qui a été identifié comme domaine modulatoire (MD) pour HBZ. II participe à l'activation de JunD par HBZ, mais son rôle précis n'a pas été étudié chez les autres protéines antisens. (? indique des fonctions/partenaires d'interaction encore inconnus pour cette région).

HBZ [53] et plus récemment, nous avons démontré un lien entre la capacité de cette protéine à induire l'expression d'une forme tronquée de JunD et son pouvoir oncogénique [60]. En plus de ces nombreuses études portant sur la protéine HBZ, plusieurs publications présentent des évidences que l'ARNm de $h b z$ serait plutôt essentiel à la modulation de la prolifération lymphocytaire par ce gène [49,61]. Il faut également préciser qu'une étude récente sur la localisation cellulaire de HBZ apporte des évidences sur une implication potentielle de cette protéine virale dans le développement de HAM/TSP [62].

\section{HTLV-2 et APH-2}

De même que HTLV-1, HTLV-2 produit un transcrit antisens codant une protéine, nommée APH-2. Cette protéine possède certaines fonctions similaires à $\mathrm{HBZ}$ : APH-2 est capable d'interagir avec CREB et inhibe ainsi la transactivation de la transcription sens du virus HTLV-2 par Tax-2 (l'équivalent de la protéine Tax du HTLV-1) [63]. APH-2 ne possède pas de domaine bZIP classique, mais plutôt un ZIP non-canonique (ncZIP) (figure 3). Ce domaine ne lui permet pas d'interagir avec CREB et APH-2 utilise plutôt à cette fin un motif riche en leucine LXXLL situé en C-terminal [64]. Cependant, au contraire de HBZ, APH-2 possède la capacité d'interagir directement avec Tax-2 grâce à une large portion de sa partie $\mathrm{C}$-terminale, lui permettant ainsi d'inhiber la transcription sens Tax/CREBdépendante. Son domaine ncZIP, bien qu' atypique, interagit avec JunB et c-Jun et les régule positivement, à la différence de HBZ [65, 66]. Des études additionnelles ont aussi montré des différences importantes entre les deux 
protéines virales : entre autres, APH-2 ne semble pas avoir un potentiel immortalisant auprès des lymphocytes $\mathrm{T}$ $[64,67]$.

\section{HTLV-3 /HTLV-4 et APH-3 et -4}

Bien que limitées, des études ont pu mettre en évidence que APH-3 et APH-4 possèdent avec HBZ et APH-2 des similarités à la fois structurelles, de fonction et d'interactome, ce qui amène à penser que leur rôle est important dans l'infection par HTLV-3 et 4. Les transcrits antisens codant pour APH-3 et APH-4 ont été détectés par RT-PCR à partir d'ADN proviral transfecté et le séquençage de ces transcrits a permis de montrer qu'ils sont épissés, tout comme les transcrits $h b z$ et $a p h-2$ (bien que seule $h b z$ semble également posséder une forme non-épissée) [68].

À l'image d'APH-2, APH-3 et APH-4 possèdent un domaine bZIP atypique, capable d'interagir avec c-Jun, JunB et JunD, mais contrairement à celui de HBZ, ce bZIP atypique active ces facteurs de transcription, menant ainsi à la stimulation du promoteur du gène hTERT [69]. Il a cependant été démontré que, tout comme HBZ et APH-2, APH-3 et APH-4 inhibent l'activation de la transcription sens sur le LTR $5^{\prime}$ induit par Tax, ce qui semble indiquer que leur rôle d'antagoniste de Tax serait en partie similaire à celui d'HBZ et APH-2, bien que les domaines impliqués dans cette inhibition n'aient pas été identifiés. APH-3 et APH-4 possèdent également des séquences s'apparentant aux séquences consensus NLS (nuclear localization signal) identifiées chez HBZ, qui pourraient être responsables de leur localisation nucléaire [68]. En fait, APH-3 se localise à la fois dans le cytoplasme et dans le noyau, alors qu'APH4 reste strictement nucléaire. De façon très intéressante, les deux protéines se trouvent associées aux nucléoles, de la même façon qu'HBZ, suggérant l'idée qu'elles pourraient avoir des fonctions similaires. Il n'existe aucune donnée sur l'implication de ces interactions sur la réplication virale. Cependant, une étude a montré que Tax et Tax3 montrent un haut taux de similarité dans leur séquence et leur fonction [70]. Il est donc possible qu'APH-3 ait un rôle dans l'infection virale. L'étude approfondie de ces deux protéines antisens reste bien sûr l'unique moyen de découvrir leurs fonctions réelles et d'estimer l'importance de leur rôle dans la réplication virale et possiblement dans certaines maladies humaines.

\section{Conclusion}

La transcription antisens chez les HTLV suscite un intérêt grandissant dans la communauté scientifique. Les études portant sur ce type d'expression permettront de décrypter les mécanismes parfois complexes mis en place par ces rétrovirus pour mener à bien leur réplication. D'un point de vue fondamental, ces recherches permettront de mieux comprendre les mécanismes régissant le contrôle de l'expression virale et donc de la réplication virale. D'un point de vue clinique, la protéine HBZ pourrait devenir une cible thérapeutique puisqu'elle semble jouer un rôle déterminant dans le développement de l'ATL. De plus, une étude par Saguta et al. (2015) présente des évidences suggérant que HBZ pourrait être utilisée dans une approche vaccinale [71]. Il est cependant tout aussi intéressant de constater que les homologues d'HBZ chez les autres membres de la famille HTLV, bien que plutôt similaires au niveau de leur mode d'expression, leur structure et leurs partenaires d'interaction, ont des comportements parfois très différents. Ainsi, une étude approfondie de l'expression et des fonctions associées aux protéines antisens des virus HTLV-2, 3 et 4 permettra de saisir le caractère potentiellement unique de la protéine HBZ et de comprendre son implication dans le développement de l'ATL chez les patients infectés par le virus HTLV-1.

Liens d'intérêts : les auteurs déclarent ne pas avoir de lien d'intérêt en rapport avec cet article.

\section{Références}

1. Poiesz BJ, Ruscetti FW, Gazdar AF, et al. Detection and isolation of type C retrovirus particles from fresh and cultured lymphocytes of a patient with cutaneous T-cell lymphoma. Proc Natl Acad Sci U S A 1980; 77 : 7415-9.

2. Yoshida MMI, Hinuma Y. Isolation and characterization of retrovirus from cell lines of human adult T-cell leukemia and its implication in the disease. Proc Natl Acad Sci U S A 1982;79:2031-5.

3. Calattini S, Chevalier SA, Duprez R, et al. Discovery of a new human T-cell lymphotropic virus (HTLV-3) in Central Africa. Retrovirology $2005 ; 2: 30$.

4. Wolfe ND, Heneine W, Carr JK, et al. Emergence of unique primate Tlymphotropic viruses among central African bushmeat hunters. Proc Natl Acad Sci U S A 2005 ; 102 : 7994-9.

5. Sherman MPSN, Dube DK, Yanagihara R, et al. Evolutionary Insights on the Origin of Human T-Cell Lymphoma/Leukemia Virus Type I (HTLVI) Derived from Sequence Analysis of a New HTLV-I Variant from Papua New Guinea. J Virol 1992; 66:2556-63.

6. Meertens L, Rigoulet J, Mauclere $\mathrm{P}$, et al. Molecular and phylogenetic analyses of 16 novel simian T cell leukemia virus type 1 from Africa : close relationship of STLV-1 from Allenopithecus nigroviridis to HTLV1 subtype B strains. Virology $2001 ; 287: 275-85$.

7. Ibrahim F, de Thé G, Gessain A. Isolation and Characterization of a New Simian T-Cell Leukemia Virus Type 1 from Naturally Infected Celebes Macaques (Macaca tonkeana) : Complete Nucleotide Sequence and Phylogenetic Relationship with the Australo-Melanesian Human TCell Leukemia Virus Type 1. J Virol 1995; 69:6980-93.

8. Filippone C, Betsem E, Tortevoye P, et al. A Severe Bite From a Nonhuman Primate Is a Major Risk Factor for HTLV-1 Infection in Hunters From Central Africa. Clin Infect Dis 2015; 60 : 1667-76. 
9. Kazanji M, Mouinga-Ondeme A, Lekana-Douki-Etenna S, et al. Origin of HTLV-1 in hunters of nonhuman primates in Central Africa. $J$ Infect Dis $2015 ; 211: 361-5$.

10. Sharp PM, Hahn BH. Origins of HIV and the AIDS pandemic. Cold Spring Harb Perspect Med $2011 ; 1$ : a006841.

11. Gessain A, Cassar O. Epidemiological Aspects and World Distribution of HTLV-1 Infection. Front Microbiol $2012 ; 3: 388$.

12. Briggs NC, Battjes RJ, Cantor KP, et al. Seroprevalence of human $T$ cell lymphotropic virus type II infection, with or without human immunodeficiency virus type 1 coinfection, among US intravenous drug users. J Infect Dis $1995 ; 172: 51-8$.

13. Nicolas $\mathrm{D}$, Ambrosioni J, Paredes R, et al. Infection with human retroviruses other than HIV-1 : HIV-2, HTLV-1, HTLV-2, HTLV-3 and HTLV-4. Expert review of anti-infective therapy $2015 ; 13$ : 947-63.

14. Hall WW, Ishak R, Zhu SW, et al. Human T lymphotropic virus type II (HTLV-II) : epidemiology, molecular properties, and clinical features of infection. J Acquir Immune Defic Syndr Hum Retrovirol 1996; 13(Suppl 1) : S204-14

15. Carneiro-Proietti AB, Sabino EC, Leao $\mathrm{S}$, et al. Human $\mathrm{T}$ lymphotropic virus type 1 and type 2 seroprevalence, incidence, and residual transfusion risk among blood donors in Brazil during 2007-2009. AIDS Res Hum Retroviruses 2012 ; 28 : 1265-72.

16. Switzer WM, Salemi M, Qari SH, et al. Ancient, independent evolution and distinct molecular features of the novel human T-lymphotropic virus type 4. Retrovirology 2009;6:9.

17. Richard L, Mouinga-Ondeme A, Betsem E, et al. Zoonotic Transmission of Two New Strains of Human T-lymphotropic Virus Type 4 in Hunters Bitten by a Gorilla in Central Africa. Clin Infect Dis 2016;63:800-3.

18. Gessain A, Rua R, Betsem E, Turpin J, Mahieux R. HTLV-3/4 and simian foamy retroviruses in humans : discovery, epidemiology, crossspecies transmission and molecular virology. Virology $2013 ; 435: 187-99$. 19. LeBreton M, Switzer WM, Djoko CF, et al. A gorilla reservoir for human T-lymphotropic virus type 4. Emerg Microbes Infect $2014 ; 3$ : e7. 20. Rizkallah G, Mahieux R, Dutartre H. Intercellular transmission of HTLV-1 : not all mechanisms have been revealed. Medecine sciences : $M / S 2015 ; 31: 629-37$.

21. Ghez D, Lepelletier $\mathrm{Y}$, Lambert $\mathrm{S}$, et al. Neuropilin-1 is involved in human T-cell lymphotropic virus type 1 entry. $J$ Virol 2006; 80 : 6844-54. 22. Manel NKF, Kinet S, Taylor N, Sitbon M, Battini JL. The Ubiquitous Glucose Transporter GLUT-1 Is a Receptor for HTLV. Cell $2003 ; 115: 449-59$.

23. Coskun AK, Sutton RE. Expression of glucose transporter 1 confers susceptibility to human T-cell leukemia virus envelope-mediated fusion. $J$ Virol 2005; 79: 4150-8.

24. Jin Q, Agrawal L, VanHorn-Ali Z, Alkhatib G. Infection of CD4+ T lymphocytes by the human $\mathrm{T}$ cell leukemia virus type 1 is mediated by the glucose transporter GLUT-1 : evidence using antibodies specific to the receptor's large extracellular domain. Virology 2006 ; 349: 184-96.

25. Jones KS, Lambert S, Bouttier M, et al. Molecular aspects of HTLV1 entry : functional domains of the HTLV-1 surface subunit (SU) and their relationships to the entry receptors. Viruses $2011 ; 3: 794-810$.

26. Watanabe T. Adult T-cell leukemia : molecular basis for clonal expansion and transformation of HTLV-1-infected T cells. Blood 2017; $129: 1071-81$.

27. Khan MY, Khan IN, Farman M, et al. HTLV-1 Associated Neurological Disorders. Current topics in medicinal chemistry 2017; 17(12): 1320-30.

28. Roucoux DF, Murphy EL. The epidemiology and disease outcomes of human T-lymphotropic virus type II. AIDS reviews $2004 ; 6$ : 144-54.

29. Duong YT, Jia H, Lust JA, et al. Short communication : Absence of evidence of HTLV-3 and HTLV-4 in patients with large granular lymphocyte (LGL) leukemia. AIDS research and human retroviruses 2008;24: 1503-5.
30. Chevalier SA, Durand S, Dasgupta A, et al. The transcription profile of Tax-3 is more similar to Tax-1 than Tax-2 : insights into HTLV-3 potential leukemogenic properties. PLoS One 2012; 7 : e41003.

31. Seiki M, Hattori S, Yoshida M. Human adult T-cell leukemia virus : molecular cloning of the provirus DNA and the unique terminal structure. Proc Natl Acad Sci U S A 1982; 79:6899-902.

32. Yao J, Wigdahl B. Human T cell lymphotropic virus type I genomic expression and impact on intracellular signaling pathways during neurodegenerative disease and leukemia. Frontiers in bioscience: a journal and virtual library $2000 ; 5$ : D138-68.

33. Kashanchi F, Brady JN. Transcriptional and post-transcriptional gene regulation of HTLV-1. Oncogene 2005 ; 24 : 5938-51.

34. Shimotohno K, Takano M, Teruuchi T, Miwa M. Requirement of multiple copies of a 21-nucleotide sequence in the U3 regions of human T-cell leukemia virus type I and typeII long terminal repeats for trans-acting activation of transcription. Proc Natl Acad Sci U S A 1986; 83 : 8112-6.

35. Jeang KT, Boros I, Brady J, Radonovich M, Khoury G. Characterization of cellular factors that interact with the human T-cell leukemia virus type I p40x-responsive 21-base-pair sequence. J Virol 1988;62: 4499-509.

36. Datta SK, Kothari NH, Fan H. In Vivo Genomic Footprinting of the Human T-Cell Leukemia Virus Type 1 (HTLV-1) Long Terminal Repeat Enhancer Sequences in HTLV-1-Infected Human T-Cell Lines with Different Levels of Tax I Activity. J Virol 2000; 74 : 8277-85.

37. Wessner R, Tillmann-Bogush M, Wigdahl B. Characterization of a glial cell-specific DNA-protein complex formed with the human $\mathrm{T}$ cell lymphotropic virus type I (HTLV-I) enhancer. J Neurovirol 1995; 1 : 62-77.

38. Adachi N, Lieber MR. Bidirectional Gene Organization : A Common Architectural Feature of the Human Genome. Cell 2002 ; 109 : 807-9.

39. Carninci $P$, Kasukawa $T$, Katayama $S$, et al. The transcriptional landscape of the mammalian genome. Science 2005 ; 309: 1559-63.

40. Lapidot M, Pilpel Y. Genome-wide natural antisense transcription : coupling its regulation to its different regulatory mechanisms. EMBO Rep 2006; $7: 1216-22$.

41. Douceron E, Kuhlmann AS, Duc Dodon M, Mahieux R. Pas de sens interdit pour la transcription virale. Virologie 2010; 14 : 193-202.

42. Miller R. Human immunodeficiency virus may encode a novel. Science $1988 ; 239: 1420$.

43. Larocca D, Chao LA, Seto MH, Brunck TK. Human T-cell leukemia virus minus strand transcription in infected T-cells. Biochem Biophys Res Commun $1989 ; 163: 1006-13$.

44. Arpin-Andre C, Laverdure S, Barbeau B, Gross A, Mesnard JM. Construction of a reporter vector for analysis of bidirectional transcriptional activity of retrovirus LTR. Plasmid $2014 ; 74$ : 45-51.

45. Yoshida M, Satou Y, Yasunaga J, Fujisawa J, Matsuoka M. Transcriptional control of spliced and unspliced human T-cell leukemia virus type 1 bZIP factor (HBZ) gene. J Virol 2008; 82 : 9359-68.

46. Gaudray G, Gachon F, Basbous J, et al. The Complementary Strand of the Human T-Cell Leukemia Virus Type 1 RNA Genome Encodes a bZIP Transcription Factor That Down-Regulates Viral Transcription. Journal of Virology 2002; 76: 12813-22.

47. Barbeau B, Mesnard JM. Does chronic infection in retroviruses have a sense? Trends in microbiology $2015 ; 23: 367-75$.

48. Barbeau B, Peloponese JM, Mesnard JM. Functional comparison of antisense proteins of HTLV-1 and HTLV-2 in viral pathogenesis. Frontiers in microbiology $2013 ; 4: 226$.

49. Satou Y, Yasunaga J, Yoshida M, Matsuoka M. HTLV-I basic leucine zipper factor gene mRNA supports proliferation of adult $\mathrm{T}$ cell leukemia cells. Proc Natl Acad Sci U S A 2006; 103 : 720-5.

50. Murata K, Hayashibara T, Sugahara K, et al. A novel alternative splicing isoform of human T-cell leukemia virus type $1 \mathrm{bZIP}$ factor (HBZ-SI) targets distinct subnuclear localization. J Virol 2006; $80: 2495-505$. 
51. Cavanagh MH, Landry S, Audet B, et al. HTLV-I antisense transcripts initiating in the $3^{\prime}$ LTR are alternatively spliced and polyadenylated. Retrovirology $2006 ; 3: 15$.

52. Usui T, Yanagihara $\mathrm{K}$, Tsukasaki $\mathrm{K}$, et al. Characteristic expression of HTLV-1 basic zipper factor (HBZ) transcripts in HTLV-1 provirus-positive cells. Retrovirology $2008 ; 5: 34$.

53. Ma G, Yasunaga J, Matsuoka M. Multifaceted functions and roles of HBZ in HTLV-1 pathogenesis. Retrovirology 2016; $13: 16$.

54. Gazon H, Lemasson I, Polakowski N, et al. Human T-cell leukemia virus type 1 (HTLV-1) bZIP factor requires cellular transcription factor JunD to upregulate HTLV-1 antisense transcription from the $3^{\prime}$ long terminal repeat. J Virol 2012;86:9070-8.

55. Arnold J, Yamamoto B, Li M, et al. Enhancement of infectivity and persistence in vivo by HBZ, a natural antisense coded protein of HTLV-1. Blood 2006; 107 : 3976-82.

56. Kuhlmann AS, Villaudy J, Gazzolo L, et al. HTLV-1 HBZ cooperates with JunD to enhance transcription of the human telomerase reverse transcriptase gene (hTERT). Retrovirology 2007; 4:92.

57. Uchida N, Otsuka T, Arima F, et al. Correlation of telomerase activity with development and progression of adult T-cell leukemia. Leuk Res $1999 ; 23: 311-6$

58. Arnold J, Zimmerman B, Li M, Lairmore MD, Green PL. Human T-cell leukemia virus type-1 antisense-encoded gene, Hbz, promotes Tlymphocyte proliferation. Blood 2008; 112:3788-97.

59. Satou Y, Yasunaga J, Zhao T, et al. HTLV-1 bZIP factor induces T-cell lymphoma and systemic inflammation in vivo. PLoS Pathog 2011; 7 : e1001274.

60. Terol M, Gazon H, Lemasson I, et al. HBZ-mediated shift of JunD from growth suppressor to tumor promoter in leukemic cells by inhibition of ribosomal protein S25 expression. Leukemia 2017;31: 2235-43.

61. Mitobe Y, Yasunaga J, Furuta R, Matsuoka M. HTLV-1 bZIP Factor RNA and Protein Impart Distinct Functions on T-cell Proliferation and Survival. Cancer Res $2015 ; 75: 4143-52$.
62. Baratella M, Forlani G, Raval GU, et al. Cytoplasmic Localization of HTLV-1 HBZ Protein : A Biomarker of HTLV-1-Associated Myelopathy/Tropical Spastic Paraparesis (HAM/TSP). PLoS Negl Trop Dis 2017; 11 : e0005285.

63. Halin M, Douceron E, Clerc I, et al. Human T-cell leukemia virus type 2 produces a spliced antisense transcript encoding a protein that lacks a classic bZIP domain but still inhibits Tax2-mediated transcription. Blood $2009 ; 114: 2427-38$

64. Yin $\mathrm{H}$, Kannian $\mathrm{P}$, Dissinger N, et al. Human T-cell leukemia virus type 2 antisense viral protein 2 is dispensable for in vitro immortalization but functions to repress early virus replication in vivo. Journal of virology $2012 ; 86: 8412-21$.

65. Marban C, McCabe A, Bukong TN, Hall WW, Sheehy N. Interplay between the HTLV-2 Tax and APH-2 proteins in the regulation of the AP-1 pathway. Retrovirology 2012;9:98.

66. Panfil AR, Dissinger NJ, Howard CM, et al. Functional Comparison of HBZ and the Related APH-2 Protein Provides Insight into Human T-Cell Leukemia Virus Type 1 Pathogenesis. J Virol 2016;90:3760-72.

67. Douceron E, Kaidarova Z, Miyazato P, et al. HTLV-2 APH-2 expression is correlated with proviral load but APH-2 does not promote lymphocytosis. The Journal of infectious diseases $2012 ; 205: 82-6$.

68. Larocque $\mathrm{E}$, Halin $\mathrm{M}$, Landry $\mathrm{S}$, et al. Human T-cell lymphotropic virus type 3 (HTLV-3)- and HTLV-4-derived antisense transcripts encode proteins with similar Tax-inhibiting functions but distinct subcellular localization. J Virol $2011 ; 85$ : 12673-85.

69. Larocque É, André-Arpin C, Mesnard JM, Switzer WM, Barbeau B. HTLV-3 and HTLV-4 antisense proteins enhance the transactivation potential of several Jun family members through interaction via their bZIP-like domain. Retrovirology 2014; 11(Suppl 1) : O72.

70. Calattini S, Chevalier SA, Duprez R, et al. Human T-cell lymphotropic virus type 3 : complete nucleotide sequence and characterization of the human tax 3 protein. Journal of virology 2006; 80 : 9876-88.

71. Sugata K, Yasunaga J, Mitobe Y, et al. Protective effect of cytotoxic T lymphocytes targeting HTLV-1 bZIP factor. Blood 2015 ; 126 : 1095-105. 